\title{
Terol BeCERRA, M., El neoconstitucionalismo Latinoamericano, Tirant lo Blanch, Valemcia, 2015, (129 págs.).
}

\author{
doi: 10.18543/ed-63(2)-2015pp301-303
}

El 24 de julio de 2008, la Asamblea Constituyente sancionó el nuevo texto de la Constitución del Ecuador, sometido a referéndum el 28 de septiembre del mismo año, aprobado por el 63,93 $\%$ de los votos emitidos ${ }^{1}$, entró en vigencia el 20 de octubre de 2015, con su publicación en el Registro Oficial.

El profesor Terol al conocer la obra: «El neoconstitucionalismo transformador. El estado y el derecho en la Constitución de $2008 »^{2}$, piensa en «criticar-

${ }^{1}$ La nueva Constitución de Ecuador fue aprobada por el 63,93\% de los votos. Ver más en: <http://www.20minutos.es/ noticia/419324/0/ecuador/constitucion/ aprobada $/$ \#xtor $=A D-15 \& x t s=467263>$.

${ }^{2}$ En abril de 2011, el profesor ecuatoriano, Ávila Santamaría, R., Abogado, y Doctor en Jurisprudencia, Pontificia Universidad Católica del Ecuador; Master of Laws, Columbia Law School, Nueva York; publicó la obra: El neoconstitucionalismo transformador. El estado y el derecho en la Constitución de 2008, Quito, Universidad Andina Simón Bolívar, Ed. Abya-Yala, 310 págs., los editores fueron Alberto Acosta Espinosa y Esperanza Martínez. Acosta EspinosA, A. estudió Economía de la Energía, Geografía Económica, Economía Industrial y Administración de Empresas en la Universidad de la desde una perspectiva estrictamente jurídica», más adelante comprende las razones del autor y «acepta como buenas las conclusiones» de Ávila Santamaría.

La obra empieza con una aproximación a la definición del neoconstitucionalismo en Europa, se exponen los componentes filosóficos, justificación y los fundamentos, de esta, corriente doctrinal producto de años de teorización académica, a lo largo de la segunda mitad del siglo XX.

El punto de partida de su investigación es el neoconstitucionalismo en Latinoamericana, siguiendo a Carbonell, afirma que, la combinación de tres elementos lo caracterizan: nuevos textos constitucionales, nuevas aproximaciones teóricas y nuevo activismo judicial, conectado a una expansión del catálogo de derechos humanos.

El nuevo constitucionalismo Latinoamericano es un fenómeno surgido

Colonia en Alemania. Fue el Presidente de la Asamblea Constituyente, desde noviembre de 2007, hasta junio de 2008 , donde se trabajó el nuevo texto de la Constitución vigente en el Ecuador. MARTíNEZ, E., acción Ecológica, organización de la sociedad civil. 
en el extrarradio de la academia, producto de la reivindicación de los movimientos sociales, en consecuencia, carece de cohesión y proposición como modelo constitucional, al encontrarse en un proceso de formación.

Otro de los puntos en común del nuevo constitucionalismo latinoamericano es el fortalecimiento de la relación entre soberanía y gobierno, bajo lo que se denomina: «formas de participación democrática» o "gobierno participativo», además de la inclusión de los sectores históricamente marginados.

Los nuevos textos constitucionales en Latinoamérica, fueron redactados con el objetivo de lograr un cambio, buscado un constitucionalismo comprometido que pueda avanzar en el camino de la justicia social, la igualdad y el bienestar de los ciudadanos, a través de la creación de las bases para una nueva institucionalidad que deje atrás el viejo constitucionalismo que se mostró incapaz de resolver los problemas fundamentales de la sociedad; les precede un objetivo esencial de cambio y, de legitimidad ofrecida por los procesos democráticos, con los que se construyen estos textos. Este es un dato importante que el autor trabajará más adelante en su obra, la idea del constitucionalismo comprometido.

La investigación plantea la pregunta sobre: las consecuencias para el modelo constitucional, de la entrada en el universo jurídico de conceptos que, en puridad, no pertenecen a este terreno, puesto que el «neoconstitucionalismo surge en el extrarradio de la academia». Asimismo, cuestiona si en realidad ¿hay algo nuevo en el neo- constitucionalismo? o si se presenta con una nueva etiqueta, cuestiones que en el pasado, han sido abordadas de otra forma.

La obra está enriquecida con los aportes del conocimiento de largos años de investigación del profesor Terol en materia Constitucional, para realizar el estudio del caso latinoamericano, mira siempre a Europa y resalta las diferencias dadas en cada uno de los modelos que analiza a lo largo del libro.

Al final de esta obra, afirma en forma concluyente que los actuales procesos constitucionales que se han dado en América Latina, se alejan progresivamente del espíritu del constitucional europeo.

Los constitucionalistas adscritos a esta corriente -asevera el profesor Terol- trabajan mucho en la idea de la «novedad de los nuevos textos», la voluntad de la Constitución, nuevas aproximaciones teóricas y nuevo activismo judicial. La ley ha dejado de ser la norma suprema del ordenamiento jurídico, para dejar su sitio a la Constitución. El neoconstitucionalismo pretende apartarse de los esquemas del positivismo teórico, donde la Constitución es un modelo neopositivista - dice Ferrajoli- y convertir al Estado de Derecho, en un Estado Constitucional de Derechos.

En cuanto a la versión del neoconstitucionalismo en Ecuador, se examina la obra: «El neoconstitucionalismo transformador. El estado y el derecho en la Constitución de 2008», de Ramiro Ávila Santamaría que recoge la caracterización del Estado y del Derecho a partir de la Constitución 2008 en Ecuador, así, entre otros aspectos 
se menciona que: el orden social que propone, es igualitarista y promueve la distribución de bienes sociales; la traslación del Estado unitario, al plurinacional; en lo económico a una economía solidaria; del Estado legal al Constitucional; del Estado de Derecho al de Derechos.

La propuesta constitucional dada en los países andinos, supera la propuesta de esta teoría del derecho transmitida desde Europa, al recoger «elementos más innovadores», con avances propios, que le son inéditos.

El «problema» es que las nuevas instituciones, no han sido creadas, ni desarrolladas, por juristas, sino por movimientos sociales, entre ellos los indígenas, por lo que requieren de la intervención de otras disciplinas científicas para su comprensión -tales como la antropología, sociología, estudios culturales, economía política-.

A lo largo de la obra el profesor Terol hace aportaciones sustanciales para la comprensión de «otros modelos democráticos», en especial el ecuatoriano, a la luz del neoconstitucionalismo latinoamericano.

En cuanto a la Constitución española, analiza el Capítulo III, del Título I, inicia el itinerario por el nacimiento de los derechos sociales, lo cual sienta las bases para comprender estos dere- chos, en la estructura de la Constitución. A través de los aporte de la Jurisprudencia en esta materia, se introduce en el concepto de la dignidad humana, pieza básica en materia constitucional, para cimentar el orden político y la paz social.

En cuanto al contenido esencial de los derechos sociales, se interpela si: ¿Es posible hablar de ello frente al silencio que guarda la Constitución en este punto? Por paradójico que parezca, esto sustenta discutir sobre ello, y se lo hace a la luz de los Instrumentos Internacionales de Derechos Humanos.

En relación a la justiciabilidad de los derechos sociales, se plantean las distintas posiciones y argumentaciones con respecto a este tema, reforzando la idea favorable a la justiciabilidad de los derechos sociales, en lo que se refiere a la Constitución española.

En el libro se advierte sobre el riesgo que corren los derechos sociales, frente a la crisis económica, en cuanto a su efectiva realización, puesto que su sola mención constitucional no garantiza que se producirán acciones positivas para su implementación por parte del Estado. Asimismo, se muestra un interesante planteamiento sobre los derechos sociales en Suecia por el criterio de priorizar entre ellos que ofrece su sistema jurídico.

Fanny Verónica Mora Navarro

Universidad Pablo de Olavide 